\title{
Comprehensive analysis of mercury pollution in the surface riverine sediments in the Haihe Basin, China
}

\author{
Wenzhong Tang ${ }^{1,2}$ (D) Baoqing Shan ${ }^{1,2} \cdot$ Yu Zhao ${ }^{1} \cdot$ Xinhui Wang ${ }^{1}$
}

Received: 7 October 2016 / Accepted: 29 June 2017 / Published online: 17 July 2017

(C) Springer-Verlag GmbH Germany 2017

\begin{abstract}
The Haihe Basin extends over $318,000 \mathrm{~km}^{2}$ or $3.3 \%$ of the total area of China, has a population of over 120 million, and is one of China's most polluted river basins. We investigated the pollution and risks from mercury $(\mathrm{Hg})$ in surface riverine sediments of this basin and found that total $\mathrm{Hg}$ concentrations in surface sediments ranged from 0.001 to $1.05 \mathrm{mg} / \mathrm{kg}$ and averaged $0.054 \mathrm{mg} / \mathrm{kg}$. Using the modified European Community Bureau of Reference standard method, we found that the exchangeable/acid-soluble, reducible, oxidizable, and residual fractions of $\mathrm{Hg}$ accounted for 9.86, 6.54, 11.0 , and $72.6 \%$ of total $\mathrm{Hg}$, respectively. The riverine sediments in the Da Qing He watershed had the highest anthropogenic enrichment of $\mathrm{Hg}$ (enrichment factor $>1.5$ ). There was a high potential ecological risk from $\mathrm{Hg}$ in the riverine sediments in the upper reaches of the Bei San He and Da Qing $\mathrm{He}$ watersheds, the middle reaches of the Luan He and Hei Long Gang watersheds, and the lower reaches of the $\mathrm{Zi} \mathrm{Ya} \mathrm{He}$ watershed. Comparison with risk assessment code showed that the riverine sediments in the Da Qing $\mathrm{He}$, Luan $\mathrm{He}$, and
\end{abstract}

Responsible editor: Philippe Garrigues

Electronic supplementary material The online version of this article (doi:10.1007/s11356-017-9681-2) contains supplementary material, which is available to authorized users.

Wenzhong Tang

wztang@rcees.ac.cn

Baoqing Shan

bqshan@ rcees.ac.cn

1 State Key Laboratory of Environmental Aquatic Chemistry, Research Center for Eco-Environmental Sciences, Chinese Academy of Sciences, Beijing 100085, People's Republic of China

2 University of Chinese Academy of Science, Beijing 100049, People's Republic of China
Tu-Hai Ma-Xia He watersheds represented a medium risk, with $16.6,11.9$, and $11.8 \%$ of $\mathrm{Hg}$ in the exchangeable/acidsoluble fraction, respectively.

Keywords Mercury · The Haihe Basin · Contamination . Riverine sediments

\section{Introduction}

The contamination of sediments with trace metals that has accompanied rapid economic development in many countries has become a serious environmental issue worldwide (Ryu et al. 2016; Zhang et al. 2015). The concentrations, speciation, sources, and toxicity of trace metal pollutants in sediments have been studied extensively in recent years (Chakraborty et al. 2014; Sundaray et al. 2011). Of all the trace metals, mercury $(\mathrm{Hg})$ has received particular attention because of the high bioaccumulation potential and toxicity of its methylated form (Leipe et al. 2013; Ma et al. 2013). Trace metal pollution in aquatic sediments has been studied intensively to facilitate effective management of aquatic ecosystems at a range of scales (Chen et al. 2015; Tang et al. 2013). Of these studies, many have considered the distribution of $\mathrm{Hg}$ in aquatic environments (Jackson 2013); to date, however, most previous studies have focused on individual catchments or rivers (Hodson et al. 2014; Wu and Cao 2010), and there have been few studies of $\mathrm{Hg}$ pollution in large river basins.

The $\mathrm{Hg}$ is ubiquitous worldwide and occurs in the environment in various forms including $\mathrm{Hg}(0)$-elemental $\mathrm{Hg}$, inorganic $\mathrm{Hg}(\mathrm{I})$, and $\mathrm{Hg}(\mathrm{II})$ species, and a series of organic forms (Leopold et al. 2010). Hg forms in sediments have been extensively studied (Horvat et al. 2003; Qiu et al. 2005), but there have been few studies of the chemical fractions of $\mathrm{Hg}$ (Sahuquillo et al. 2003; Yang et al. 2009), especially in large 
basins. It has been pointed out that chemical fractions should be used to study the mobility and bioavailability of $\mathrm{Hg}$ rather than total Hg (Islam et al. 2015), and environmental risk evaluations or remediation strategies should be based on individual species of $\mathrm{Hg}$ or their binding to different phases of the matrix rather than the total concentrations of $\mathrm{Hg}$ (Sahuquillo et al. 2003). The retention and accumulation of $\mathrm{Hg}$ in sediment are closely linked to the chemical form of the metal, and to the variable environmental conditions, such as the oxygen content or the redox conditions. $\mathrm{Hg}$ distribution in sediments is mainly governed by the high stability of its associations with sulfide and high molecular weight organic matter (Biester et al. 2000; Sahuquillo et al. 2003). Consequently, the mobility of $\mathrm{Hg}$ in sediments can be assessed from the chemical fractions determined in the sequential extraction procedure developed by the Bureau of Reference of the European Community.

The standard method of the European Community Bureau of Reference (BCR) is a sequential extraction that has been used widely to determine the chemical speciation of heavy metals (Arain et al. 2008; Gao and Chen 2012). The bioavailability of a metal is related to the concentrations of the exchangeable/acid soluble (B1), reducible (B2), and oxidizable fractions (B3); the residual fraction (B4) is not bioavailable and remains stable for long periods (Rosado et al. 2016; Yin et al. 2014; Zhang et al. 2014). Heavy metals in the B1 fraction of sediments are considered unstable because they can be released to the aqueous phase, where they become more bioavailable (Gao and Chen 2012). The contribution of the B1 fraction to the total concentration can be determined from the risk assessment code (RAC), which is widely used to estimate the bioavailability of and risks posed by heavy metals in sediments (Passos et al. 2010; Singh et al. 2005). A risk assessment code based on the $\mathrm{B} 1$ fraction of $\mathrm{Hg}^{2+}$ can be used to evaluate the mobility and bioavailability of $\mathrm{Hg}$ in sediments. For example, an increase in $\mathrm{Hg}$ mobility may result in uptake of monomethyl $\mathrm{Hg}(\mathrm{MeHg})$ into organisms via predation. On the other hand, the B4 fraction of heavy metals (including $\mathrm{Hg}$ ) is generally chemically stable, only slightly toxic, and is not available for uptake by organisms.

The Haihe Basin is one of the most developed areas in China, with a large population and a highly developed economy (Chen et al. 2012). In recent years, the level of trace metal pollution in the Haihe Basin has increased, causing serious implications for aquatic ecosystems (Xiao et al. 2011). Previous studies have reported trace metal pollution in the Haihe Basin with, of the studied metals, most anthropogenic enrichment from $\mathrm{Cd}, \mathrm{Zn}$, and $\mathrm{Cu}$, and a high potential ecological risk from Cd (Tang et al. 2013). This kind of information is not available for $\mathrm{Hg}$, as it has not been studied as much as other sediment-associated metals (Chakraborty et al. 2014). Indeed, this study presents for the first time the distribution and speciation of $\mathrm{Hg}$ in riverine sediments described for a basin as large as the Haihe Basin in China. The aims of this study were (1) to investigate $\mathrm{Hg}$ concentrations and speciation in surface riverine sediments, (2) to identify $\mathrm{Hg}$ sources and the degree of contamination from values of the enrichment factor $(\mathrm{EF})$ and geo-accumulation index $\left(I_{\text {geo }}\right)$, and (3) to evaluate the risks from $\mathrm{Hg}$ using the potential ecological risk (PER) index and RAC.

\section{Materials and methods}

\section{Study area}

The Haihe Basin $\left(35^{\circ}-43^{\circ} \mathrm{N}, 112^{\circ}-120^{\circ} \mathrm{E}\right)$ spans the cities of Beijing and Tianjin; the provinces of Hebei, Shanxi, Shandong, Liaoning, and Henan; and the autonomous region of Inner Mongolia, in North China (Fig. 1). Of all the water resources in China, the Haihe Basin ranks among the scarcest. Along with the rapid development of the economy, the amount of domestic sewage produced and discharged into the rivers has increased, causing a sharp deterioration in the aquatic ecosystems of the Haihe Basin. As shown in Fig. 1, the basin comprises nine major watersheds, named the Luan He (LH), Bei San He (BSH), Yong Ding He (YDH), Da Qing He (DQH), Hai-He Gan-Liu (HG), Zi Ya He (ZYH), Hei Long Gang (HLG), Zhang Wei He (ZWH), and Tu-Hai Ma-Xia He (TMH).

\section{Sample collection and analysis}

A total of 410 sediment sampling sites were selected (Fig. 1). Surface sediments were collected to a depth of $10 \mathrm{~cm}$ from 220 stations between May and August, 2013, from the LH, BSH, YDH, DQH, HG, ZYH, HLG, ZWH, and TMH watersheds using a Peterson grab sampler. Surface sediment samples were only collected from 220 sites because some of the riverbed surfaces were hard and were composed almost completely of sand and gravel; other rivers had been dried up for many years, and some rivers had been dredged, and sediments had been removed to remediate contaminated sediment. Three cores of undisturbed sediment were collected at each station at randomly selected points that were between 50 and $100 \mathrm{~m}$ apart. The sediment samples were sealed in clean polyethylene bags and placed into a cool box at the sampling site. On arrival at the laboratory, the cooled samples were frozen for being freeze-dried at $-50{ }^{\circ} \mathrm{C}$ and then were ground and passed through a 100 -mesh sieve before analysis.

A portion of each sediment sample $(0.500 \mathrm{~g})$ was digested in a 3:1 mixture of hydrochloric acid and nitric acid (aqua regia) before analysis for total $\mathrm{Hg}$ (Bao 2000; Bloom et al. 2003). Another portion $(0.100 \mathrm{~g})$ was digested in a 5:1 mixture of hydrofluoric acid and perchloric acid in a microwave oven (MARS Xpress; CEM, Matthews, NC, USA) before analysis for Fe (Tessier et al. 1979); the digestion conditions are 


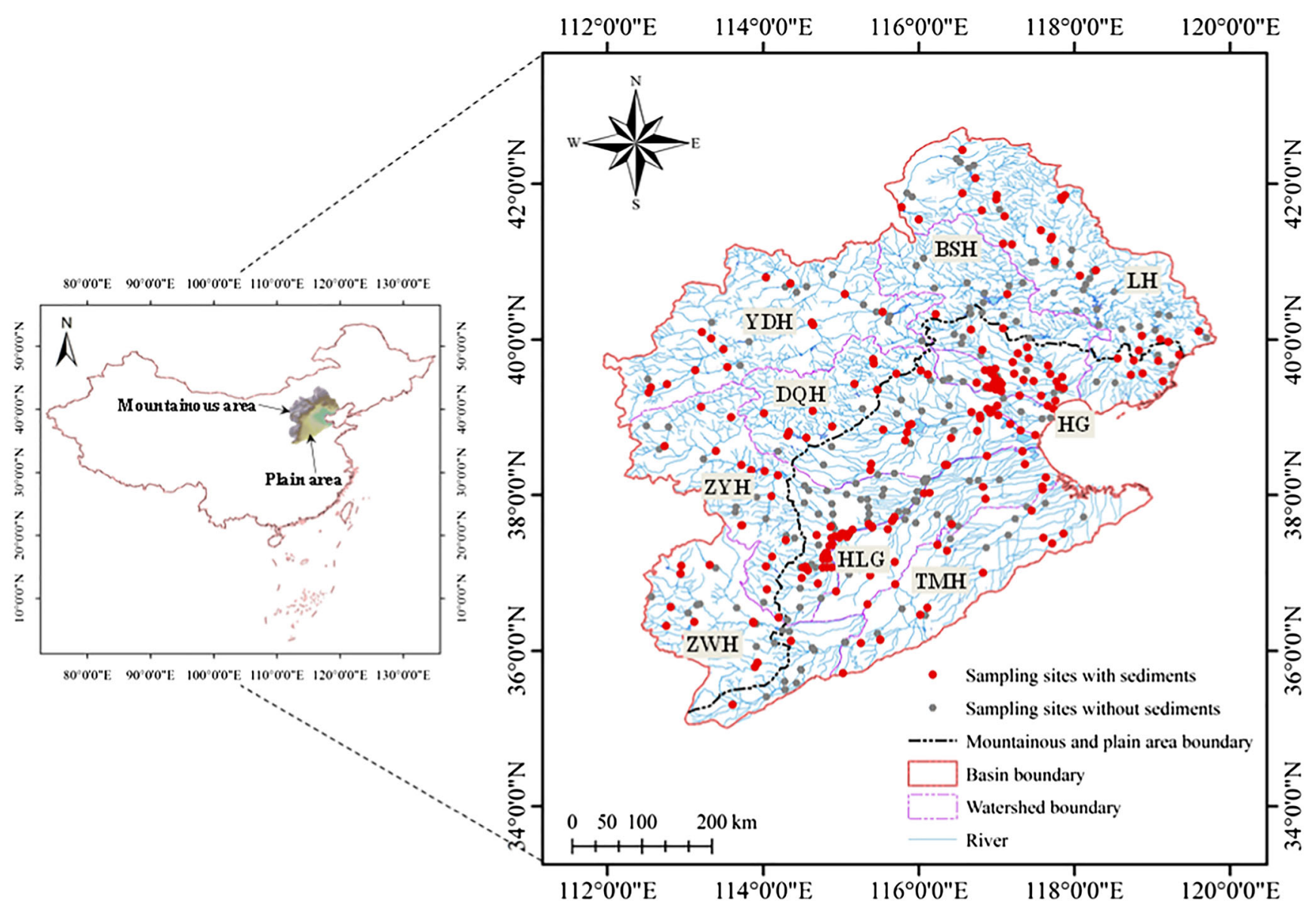

Fig. 1 Map of the sediment sampling stations in the rivers of the Haihe Basin, China

provided in Table S1. The precision and accuracy of the $\mathrm{Hg}$ results were assessed by comparing with the results from the analysis of a standard sediment reference material GBW07303a (National Institute of Metrology, Beijing, China). The Hg recoveries were between 90 and $110 \%$.

We used a modified three-stage BCR sequential extraction procedure to determine the different chemical fractions of $\mathrm{Hg}$ in the sediments (Arain et al. 2008), namely the proportions of $\mathrm{Hg}$ in the B1 (acetic acid, $0.11 \mathrm{~mol} / \mathrm{L}$ ), B2 (hydroxylamine hydrochloride, $0.1 \mathrm{~mol} / \mathrm{L}$ ), B3 (hydrogen peroxide, $8.8 \mathrm{~mol} / \mathrm{L}$, then ammonium acetate, $1.0 \mathrm{~mol} / \mathrm{L}$ ), and $\mathrm{B} 4$ (aqua regia) fractions. All of the above solutions were stored at $4{ }^{\circ} \mathrm{C}$ until analysis. We measured the concentrations of $\mathrm{Hg}$, with a detection limit of $0.005 \mu \mathrm{g} / \mathrm{L}$, by atomic fluorescence spectrometry (AFS) (AF-610B, Beijing Ruili Analytical Instrument Company, China), and Fe by inductively coupled plasma optical emission spectrometry (ICP-OES, Optima 2000DV; PerkinElmer, Waltham, MA, USA). We assessed the accuracy of the optimized BCR procedure by comparing with the properties of a standard sediment reference material GBW07436 (National Institute of Metrology, Beijing, China). The recoveries of the sequential extraction were calculated using the following equation (Arain et al. 2008):

$$
\begin{aligned}
& \operatorname{Recovery}(\%) \\
& =\left[\left(C_{\text {step } 1}+C_{\text {step } 2}+C_{\text {step } 3}+C_{\text {step } 4}\right) / C_{\text {total digestion }}\right] \\
& \quad \times 100
\end{aligned}
$$

The recoveries of the chemical fractions of the heavy metals ranged from 92 to $105 \%$, and the relative standard deviation (used to indicate the precision of the method) was less than $5 \%$. Before use, all plastic and glassware were soaked in $10 \% \mathrm{HNO}_{3}(v / v)$ for at least 2 days, and then were immersed in, and rinsed with, ultrapure water.

\section{Assessment approaches and statistical analyses}

The EF is derived by standardizing a measured element against a reference value. The reference element in this study was iron $(\mathrm{Fe})$, the element most widely used for standardization. The EF values of heavy metals were calculated with the following equation (Bhuiyan et al. 2010):

$\mathrm{EF}=\left(C_{n} / C_{\mathrm{Fe}}\right) \times\left(B_{n} / B_{\mathrm{Fe}}\right)^{-1}$, 
where $C_{n}$ and $C_{\mathrm{Fe}}$ are the concentrations of the examined and reference metals in the sediments, respectively, and $B_{n}$ and $B_{\mathrm{Fe}}$ are the background concentrations of the examined and reference metals in the reference sediments, respectively. In this study, a soil background value for the Haihe Basin of $\mathrm{Hg}$ of $0.065 \mathrm{mg} / \mathrm{kg}$ was adopted as the baseline value (CNEMC 1990). The different classes of this index are shown in Table S2.

The $I_{\text {geo }}$ is another standard assessment model that facilitates evaluation of heavy metal pollution in sediments by comparing current concentrations with pre-industrial levels (Müller 1969). The $I_{\text {geo }}$ is defined by the following equation:

$I_{\text {geo }}=\log _{2}\left(\frac{C_{n}}{K \times B_{n}}\right)$,

where $C_{n}$ is the concentration of the heavy metal, $B_{n}$ is the corresponding background heavy metal concentration, and $K$ is the background matrix correction factor $(K=1.5)$. The classes of the $I_{\text {geo }}$ that indicate the degree of sediment pollution caused by heavy metals are shown in Table S2.

The PER index was developed by Håkanson (1980) to assess the degree of contamination of trace metals in sediments. The equation for calculating the PER index of $\mathrm{Hg}$ is as follows:

$E_{r}^{i}=T_{r}^{i} \times C_{f}^{i}=T_{r}^{i} \times\left(C_{s}^{i} / C_{n}^{i}\right)$,

where $C_{S}^{i}$ is the concentration of the element in the samples, $C_{n}^{i}$ is the background concentration of the element, $C_{f}^{i}$ is the single element pollution factor, $E_{r}^{i}$ is the PER index of an individual element, and $T_{r}{ }_{r}$ is the biological toxicity factor of an individual element, which is defined as $\mathrm{Hg}=40$ (Yang et al. 2009). The different levels of this index are shown in Table S2.

The RAC is based on the occurrence of different forms of heavy metals in the sediments. This index assesses the availability of metals in solution from the percentage of the B1 fraction in sediments (Singh et al. 2005). The classification for this index is provided in Table S2. Details of the abovementioned methods are provided in the Supplementary Materials (Table S2). We analyzed the Hg dataset with SPSS (version 18.0 for Windows) and processed the experimental data with ArcGIS 10.1.

\section{Results and discussion}

\section{Total $\mathrm{Hg}$ concentrations and $\mathrm{Hg}$ speciation in surface sediments}

Total $\mathrm{Hg}$ concentrations in surface riverine sediments of the Haihe Basin ranged from 0.001 to $1.05 \mathrm{mg} / \mathrm{kg}$, and averaged
$0.054 \mathrm{mg} / \mathrm{kg}$ (Fig. 2). The Hg concentrations exceeded the background values at 39 of the 220 sampling sites. The average total $\mathrm{Hg}$ concentrations in the BSH, DQH, HLG, LH, $\mathrm{TMH}, \mathrm{YDH}, \mathrm{ZWH}$, and ZYH watersheds were 0.044 , $0.058,0.108,0.052,0.043,0.030,0.028$, and $0.065 \mathrm{mg} / \mathrm{kg}$, respectively (Table $\mathrm{S} 3$ ). The $\mathrm{Hg}$ concentrations were highest in the middle reaches of the LH watershed, in the middle reaches of the HLG watershed, and in the middle and lower reaches of the ZYH watershed.

There was considerable variation in the proportions of the four $\mathrm{Hg}$ fractions in the surface sediments (Figs. 3 and $\mathrm{S} 1$ ). The B1, B2, B3, and B4 fractions accounted for, on average, 9.86, 6.54, 11.0, and $72.6 \%$ of total $\mathrm{Hg}$ and ranged from 0 to $77.5 \%, 0$ to $38.6 \%, 0$ to $65.6 \%$, and from 8.85 to $98.4 \%$, respectively. The $\mathrm{B} 4$ fraction of $\mathrm{Hg}$, the most stable fraction, dominated in the surface sediments of the Haihe Basin, which indicates that the risk to the aquatic ecosystem from $\mathrm{Hg}$ is extremely low, and the water can be considered safe (Yang et al. 2009). Total $\mathrm{Hg}$ concentrations ranged from 0.010 to $0.251,0.011$ to $0.311,0.014$ to $0.173,0.001$ to $0.093,0.012$ to $0.182,0.003$ to $0.136,0.004$ to 0.073 , and from 0.006 to $0.256 \mathrm{mg} / \mathrm{kg}$ in the riverine sediments from the $\mathrm{BSH}, \mathrm{DQH}$, HLG, LH, TMH, YDH, ZWH, and ZYH watersheds, respectively (Fig. S2). The total $\mathrm{Hg}$ concentrations and the $\mathrm{Hg}$ speciation in the sediments of the Haihe Basin and other selected water bodies are compared in Table S4. The average Hg concentrations $(0.045 \mathrm{mg} / \mathrm{kg})$ in surface riverine sediments of the Haihe Basin were lower than those in other places, and the B4 fraction also dominated in other places (Table S4). Total $\mathrm{Hg}$ concentrations exceeded the background level at $17.7 \%$ of the sampling sites, and the threshold effect concentration (TEC) at $5.00 \%$ of the sampling sites (Table S5).

\section{Sources of $\mathrm{Hg}$ contamination in surface sediments}

Trace metals in sediments have two main sources: natural and anthropogenic (Feng et al. 2004). We calculated the EF value for each watershed to evaluate the influence of anthropogenic activities on $\mathrm{Hg}$ concentrations in the sediments of the Haihe Basin (Fig. 4). DQH, with a mean EF value of 2.69, was the most contaminated watershed, followed by the HLG, LH, BSH, ZYH, ZWH, TMH, and YDH watersheds, which had mean EF values of $1.43,0.961,0.865,0.800,0.701,0.598$, and 0.483 , respectively. The distributions of the EF values and the $\mathrm{Hg}$ concentrations were similar. The average, minimum, and maximum $\mathrm{EF}$ values for $\mathrm{Hg}$ were 1.12, 0.011, and 41.6, respectively. As shown in Fig. 4, only $1.40 \%$ of the $\mathrm{Hg} \mathrm{EF}$ values in the surface sediments were 1.5 or higher, and most were less than 1.5, which shows that $\mathrm{Hg}$ enrichment in the Haihe Basin was mainly from natural weathering and erosion (Table S2).

The Hg EF values were different for each river system in the Haihe Basin. The mean Hg EF in the sediments of the 


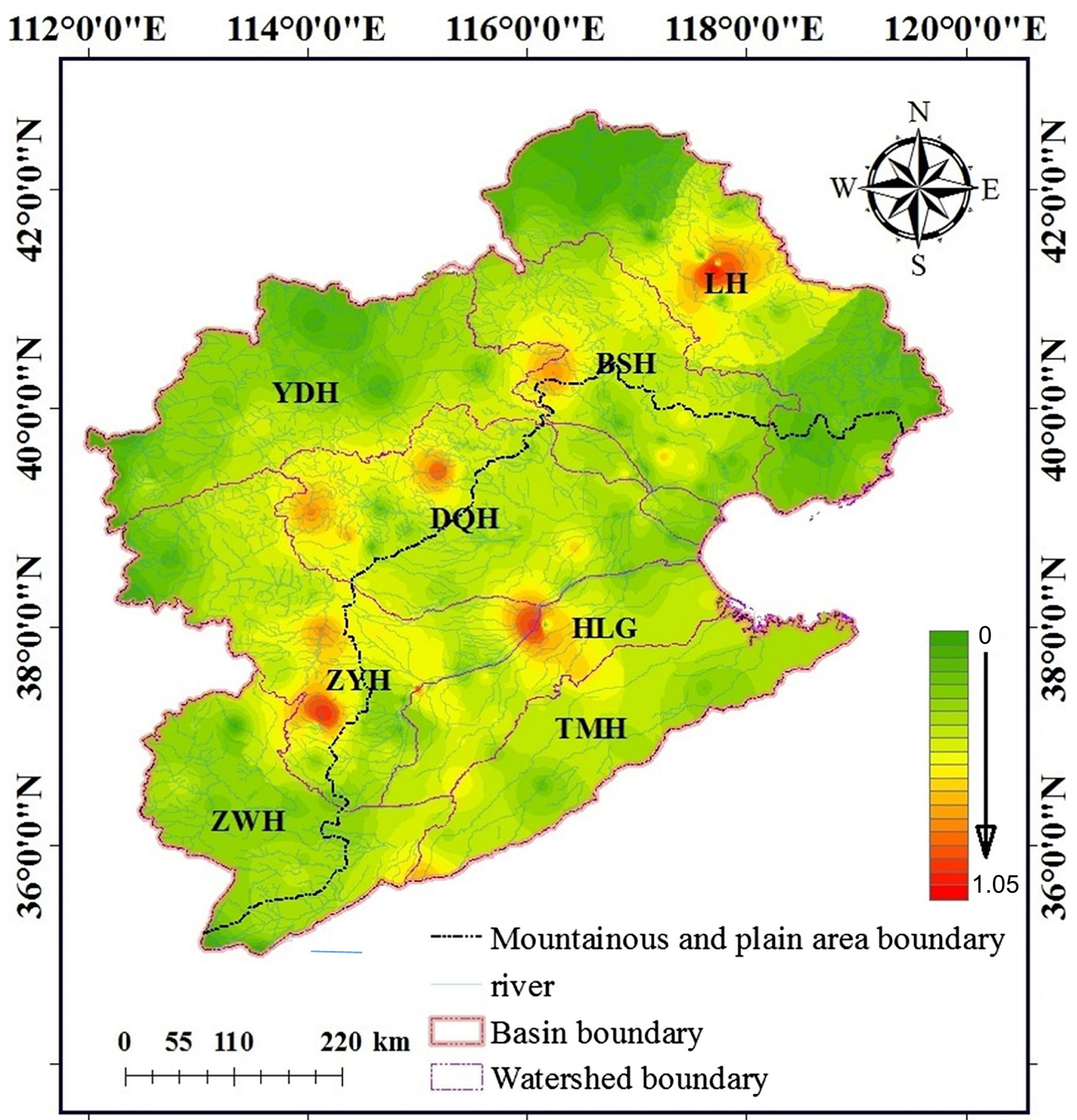

\section{$112^{\circ} 0^{\prime} 0^{\prime \prime} \mathrm{E} \quad 114^{\circ} 0^{\prime} 0^{\prime \prime} \mathrm{E} \quad 1^{\circ} 6^{\circ} 0^{\prime} 0^{\prime \prime} \mathrm{E} \quad 1^{\circ} 8^{\circ} 0^{\prime} 0^{\prime \prime} \mathrm{E} \quad 120^{\circ} 0^{\prime} 0^{\prime \prime} \mathrm{E}$}

Fig. 2 Spatial distribution of total $\mathrm{Hg}$ concentrations in surface riverine sediments of the Haihe Basin $(\mathrm{mg} / \mathrm{kg})$. The map was created and edited in ArcGIS (version 10.1, ESRI, USA) using the inverse distance weighted (IDW) interpolation method

DQH watershed was substantially more than 1.5 and exceeded 1.5 at $19.0 \%$ of the sampling points. The percentage of sampling sites with an $\mathrm{Hg}$ enrichment factor greater than 1.5 was highest in the $\mathrm{BSH}(20 \%)$, and this percentage decreased in the other watersheds in the following order: $\mathrm{DQH}>\mathrm{HLG}>$ $\mathrm{TMH}>\mathrm{ZYH}>\mathrm{ZWH}>\mathrm{LH}>\mathrm{YDH}$. While anthropogenic sources had some influence on surface sediments in the eight major river systems, natural weathering and erosion and other natural factors were more important.

The mean $I_{\text {geo }}$ value was highest in the HLG watershed $(-0.668)$, which indicates that this was the most contaminated watershed. The mean $I_{\text {geo }}$ values in the DQH, ZYH, TMH, $\mathrm{BSH}, \mathrm{ZWH}, \mathrm{YDH}$, and $\mathrm{LH}$ watersheds were $-1.38,-1.40$, $-1.51,-1.75,-2.12,-2.29$, and -2.96 , respectively (Fig. 4). 


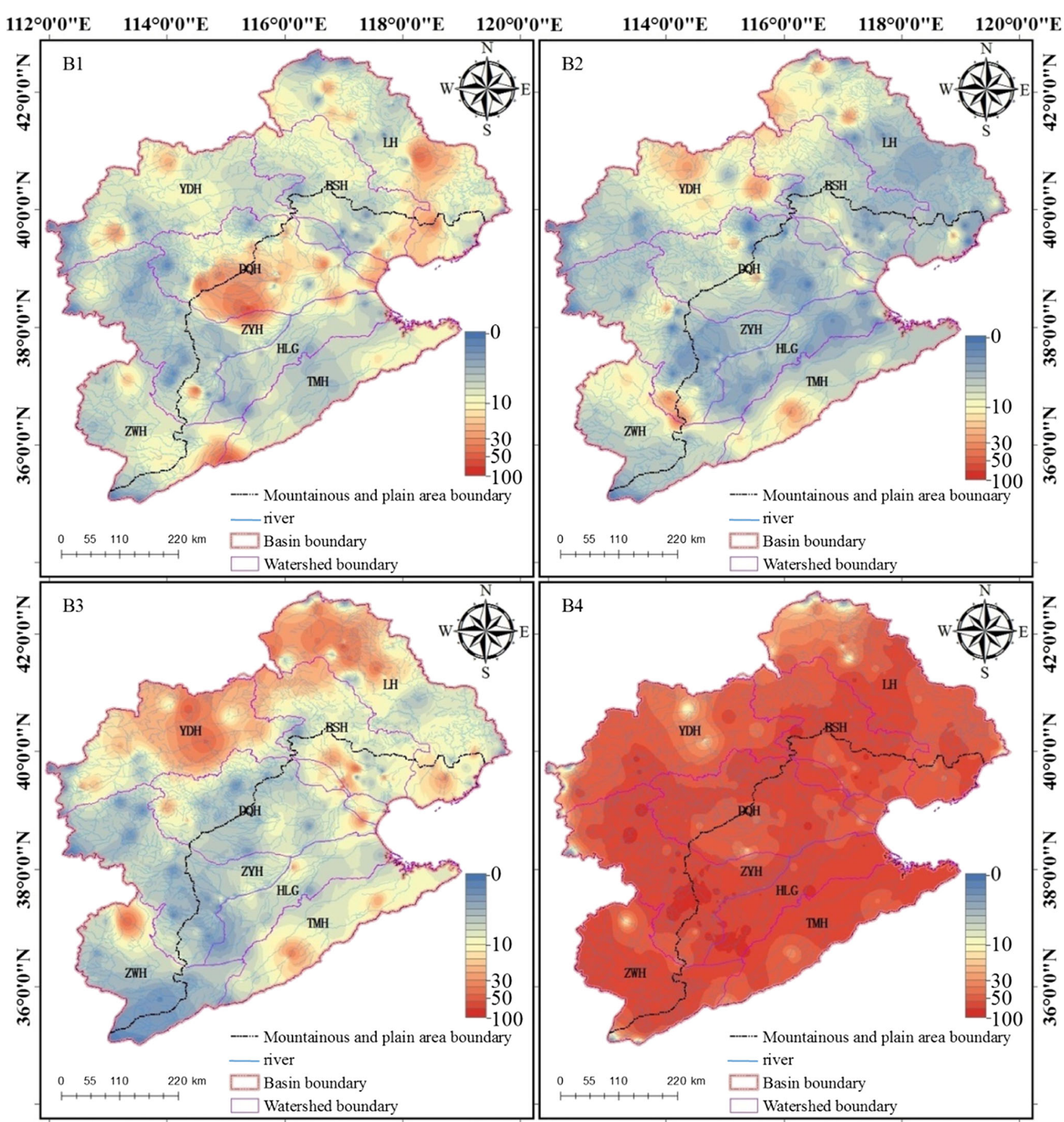

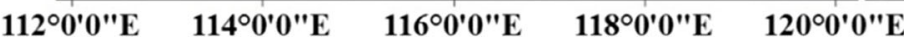

$114^{\circ} 0^{\prime} 0 " \mathrm{E} \quad 116^{\circ} 0^{\prime} 0^{\prime \prime E} \quad 118^{\circ} 0^{\prime} 0^{\prime \prime} \mathrm{E} \quad 120^{\circ} 0^{\prime} 0^{\prime \prime} \mathrm{E}$

Fig. 3 The proportion (\%) of the B1 (exchangeable/acid soluble), B2 (reducible), B3 (oxidizable), and B4 (residual) fractions in surface riverine sediments of the Haihe Basin derived from the modified BCR

When classified with this index (Table S4), $100 \%$ of the samples from the ZWH watersheds were clean; more than $90 \%$ of the samples from the LH, YDH, BSH, and TMH watersheds were clean, and $80 \%$ of the samples from the $\mathrm{DQH}, \mathrm{ZYH}$, and HLG watersheds were clean. Overall, the $I_{\text {geo }}$ classification shows that the surface sediments of the Haihe Basin are only slightly polluted with $\mathrm{Hg}$. standard method. The maps were created and edited using ArcGIS (version 10.1, ESRI, USA) with the inverse distance weighted (IDW) interpolation method

\section{Hg risk assessment in surface sediments}

The average values of the PER index in the surface riverine sediments of each watershed were ranked in the following order from highest to lowest: HLG (66.5) > ZYH (39.9) > DQH (35.5) $>\mathrm{LH}$ (31.9) $>\mathrm{BSH}(27.2)>\mathrm{TMH}(26.7)>\mathrm{YDH}(18.6)>\mathrm{ZWH}$ (16.9) (Fig. 5). The $\mathrm{Hg} E_{r}^{i}$ values of the HLG watershed surface 


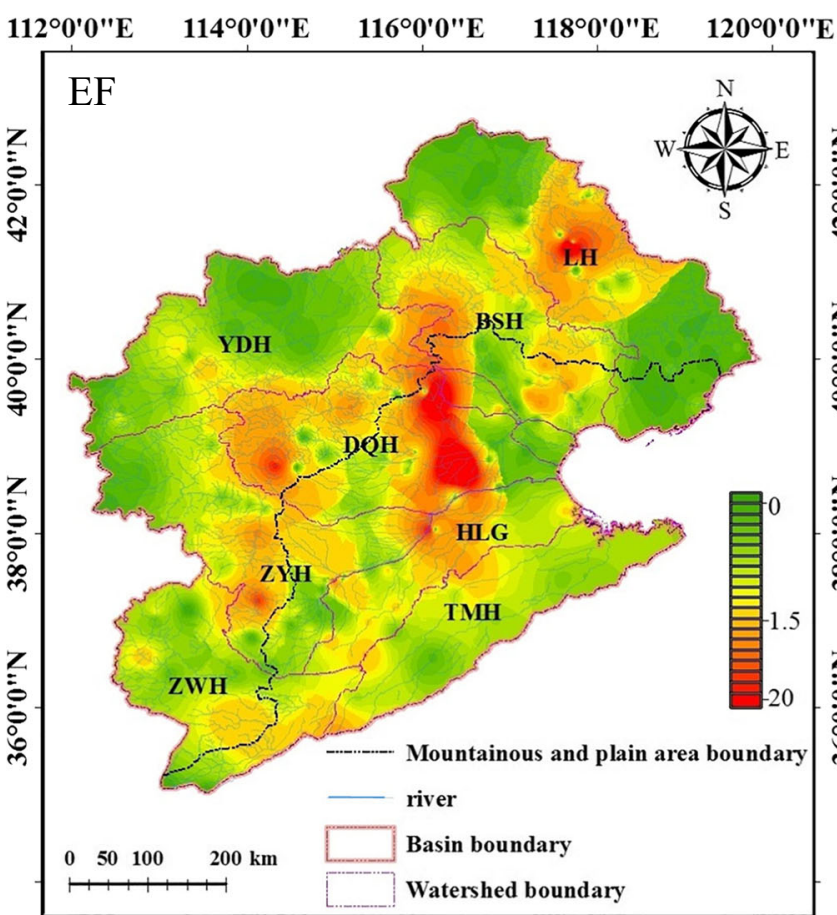

$112^{\circ} 0^{\prime} 0^{\prime \prime} \mathrm{E} \quad 114^{\circ} 0^{\prime} 0^{\prime \prime} \mathrm{E} \quad 1^{\circ} 6^{\circ} 0^{\prime} 0^{\prime \prime} \mathrm{E} \quad 118^{\circ} 0^{\prime} 0^{\prime \prime} \mathrm{E} \quad 1^{\circ} 0^{\circ} 0^{\prime} 0^{\prime \prime} \mathrm{E}$

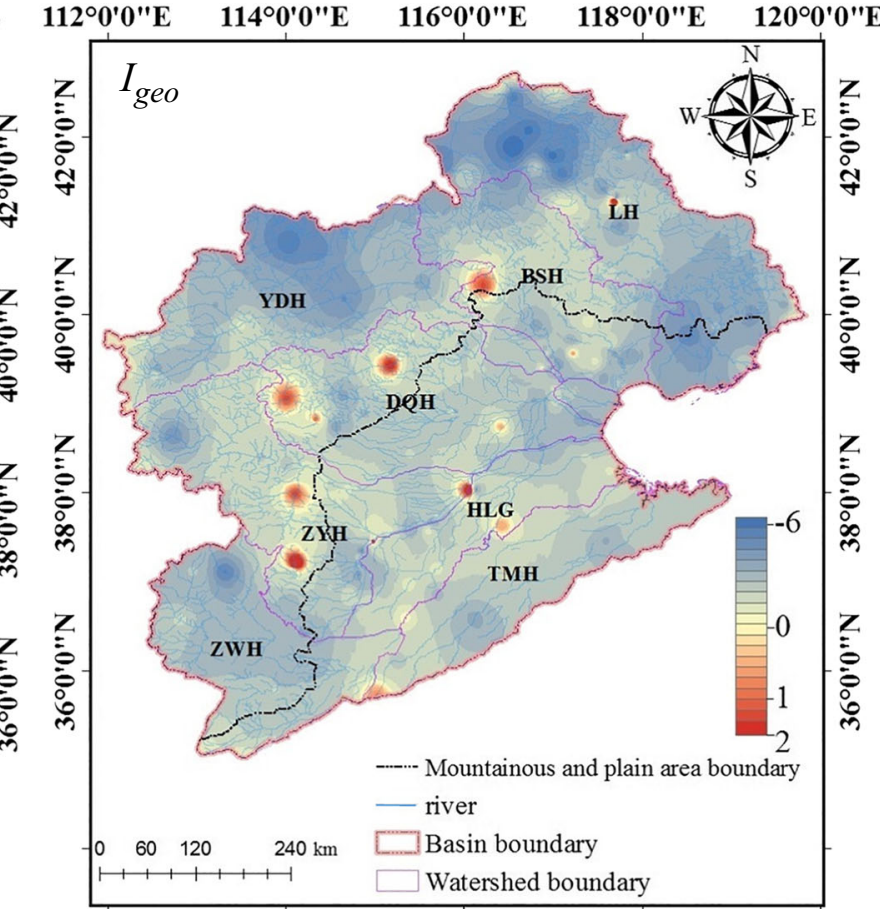

$112^{\circ} 0^{\prime} 0$ " E $\quad 114^{\circ} 0^{\prime} 0$ "E $\quad 116^{\circ} 0^{\prime} 0^{\prime \prime} \mathrm{E} \quad 118^{\circ} 0^{\prime} 0^{\prime \prime} \mathrm{E} \quad 120^{\circ} 0^{\prime} 0^{\prime \prime} \mathrm{E}$

Fig. 4 Values of the enrichment factor $(\mathrm{EF})$ and geo-accumulation index $\left(I_{\mathrm{geo}}\right)$ of $\mathrm{Hg}$ in surface riverine sediments of the Haihe Basin. The map was created and edited using ArcGIS (version 10.1, ESRI, USA) with the inverse distance weighted (IDW) interpolation method

sediments ranged from 8.48 to 418 , with an average of 66.5 , and indicate moderate risk (Table S2). In this watershed, $6.25 \%$ of the samples were classified as representing a serious risk, while $31.3 \%$ of the samples represented a moderate-risk level. The mean $E_{r}^{i}$ values for the other watersheds were less than 40 , indicating a low risk of $\mathrm{Hg}$ pollution and low levels of $\mathrm{Hg}$ contamination in sediments in these rivers. However, the mean $E_{r}^{i}$ value indicated a high level of risk in the upper reaches of the

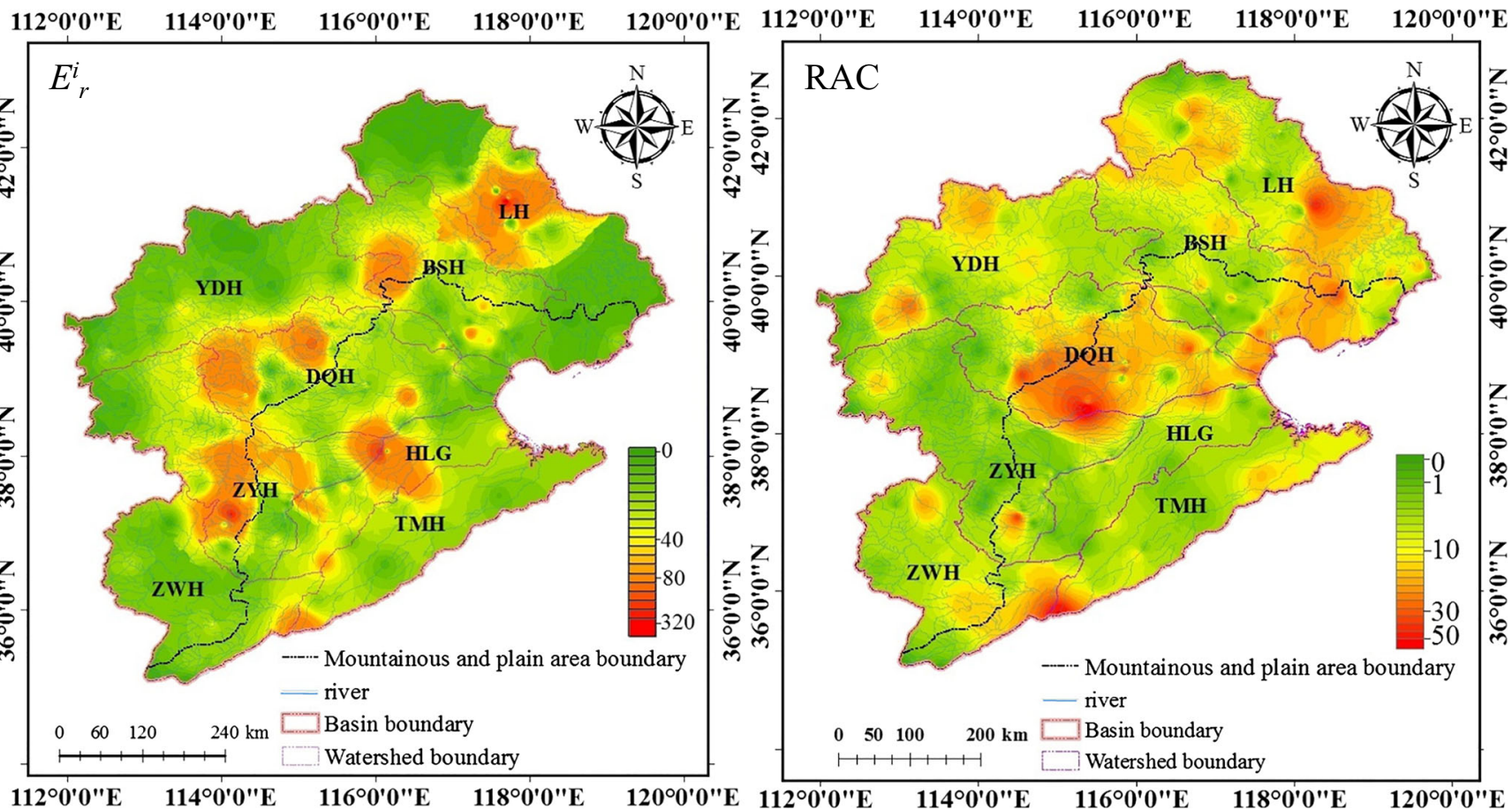

Fig. 5 Risk assessment of $\mathrm{Hg}$ in surface riverine sediments of the Haihe Basin, potential ecological risk index $\left(E^{i}\right)$, and risk assessment code (RAC, $\%$ ). The map was created and edited using ArcGIS (version 10.1, ESRI, USA) with the inverse distance weighted (IDW) interpolation method 
$\mathrm{BSH}$ and DQH watersheds, the middle reaches of the $\mathrm{LH}$ and HLG watersheds, and the lower reaches of the ZYH watershed (Fig. 5), which may reflect mining and industrial development in these areas. The pollution should be controlled in these areas so as to improve the river sediment quality and reduce the associated ecological risk.

We also used the RAC method to evaluate the degree of risk associated with $\mathrm{Hg}$ in surface sediments from the B1 fraction. The B1 fraction in the surface sediments represented 16.6, 11.9, $11.8,9.84,8.62,7.63,6.12$, and $5.15 \%$ in the DQH, LH, TMH, BSH, ZWH, YDH, ZYH, and HLG watersheds, respectively (Fig. 5). The average percentages of the B1 fraction in the $\mathrm{DQH}, \mathrm{LH}$, and TMH watersheds indicated moderate-risk levels. The B1 fraction accounted for between 0.64 and $77.5 \%$ of total $\mathrm{Hg}$ and accounted for an average of $16.6 \%$, in the $\mathrm{DQH}$ watershed, indicating a moderate-risk level; $2.78,11.1$, and $38.9 \%$ of the samples in this watershed presented very high, high, and moderate-risk levels, respectively. The B1 of metals is generally considered as the most mobile and bioavailable fraction of most metals, and while the proportion of the acid exchangeable $\mathrm{Hg}^{2+}$ was generally lower than the other fractions, it is still a useful indicator of the mobility and bioavailability of $\mathrm{Hg}^{2+}$ in sediments (Liang et al. 2012).

The PER method was developed based on the total concentration of $\mathrm{Hg}$, while the RAC was determined based on the proportion of $\mathrm{Hg}$ occurring in the B1 fraction (Håkanson 1980; Singh et al. 2005). In this study, the risk assessment results were somewhat different from the PER and RAC values in some sediment samples, probably because of the different forms of $\mathrm{Hg}$ present in the sediments. For example, in HLG surface riverine sediments, the average value of $\mathrm{Hg} E_{r}^{i}$ was 66.5 indicating moderate risk (PER method), but the $\mathrm{Hg}$ occurred mainly as the B4 fraction, the most stable fraction, with only a very small proportion in the $\mathrm{B} 1$ fraction, indicating a relatively low ecological risk (RAC method). Therefore, the results from PER and RAC were not contradictory, but should be combined to verify the risk of sediments. In the Haihe Basin, the riverine sediments posed a high PER from $\mathrm{Hg}$ based on its total concentrations in the upper reaches of the BSH and DQH watersheds, the middle reaches of the LH and HLG watersheds, and the lower reaches of the $\mathrm{ZYH}$ watershed, while only the riverine sediments in the $\mathrm{DQH}, \mathrm{LH}$, and TMH watersheds represented a medium risk based on the proportion of $\mathrm{Hg}$ occurring in the B1 fraction (16.6, 11.9, and $11.8 \%$, respectively). Our results suggest that it is important to monitor and pay attention to $\mathrm{Hg}$ contamination in the surface riverine sediments in the $\mathrm{DQH}$ and $\mathrm{LH}$ watersheds of the Haihe Basin.

\section{Conclusion}

We assessed the $\mathrm{Hg}$ contamination in surface riverine sediments of the Haihe Basin. Concentrations of $\mathrm{Hg}$ ranged from
0.001 to $1.05 \mathrm{mg} / \mathrm{kg}$, and $\mathrm{Hg}$ was mainly in the $\mathrm{B} 4$ fraction, followed by, in descending order, the B3, B2, and B1 fractions. Concentrations of $\mathrm{Hg}$ in surface sediments were higher in the LH, HLG, and ZYH watersheds. Most sedimentassociated $\mathrm{Hg}$ appeared to be derived from natural sources, rather than anthropogenic pollution. The average PER values for surface sediments in each watershed decreased in the following order: $\mathrm{HLG}>\mathrm{ZYH}>\mathrm{ZYH}>\mathrm{LH}>\mathrm{BSH}>\mathrm{TMH}>$ $\mathrm{YDH}>\mathrm{ZWH}$. Sediments in the HLG watershed were moderately polluted, while the PER values for the other seven watersheds were low. We found high PER values at many sampling sites throughout the Haihe Basin, mainly in the BSH, DQH, LH, and ZYH watersheds. The RAC values showed that there was a moderate risk from $\mathrm{Hg}$ in sediments in the $\mathrm{DQH}, \mathrm{LH}$, and TMH watersheds, but low risks in the other watersheds. This information will help support the development of effective management strategies to control $\mathrm{Hg}$ pollution in the Haihe Basin.

Acknowledgements This research was supported by the Youth Innovation Promotion Association CAS (Wenzhong Tang, 2017059), the Major Science and Technology Program for Water Pollution Control and Treatment (No. 2012ZX07203-006), and the special fund from the State Key Joint Laboratory of Environment Simulation and Pollution Control (No. 17L02ESPC). We also acknowledge the support received by Wenzhong Tang from the Chinese Scholarship Council (CSC Grant 201604910224).

\section{References}

Arain MB, Kazi TG, Jamali MK, Afridi HI, Jalbani N, Sarfraz RA, Baig JA, Kandhro GA, Memon MA (2008) Time saving modified BCR sequential extraction procedure for the fraction of $\mathrm{Cd}, \mathrm{Cr}, \mathrm{Cu}, \mathrm{Ni}, \mathrm{Pb}$ and $\mathrm{Zn}$ in sediment samples of polluted lake. J Hazard Mater 160: 235-239

Bao SD (2000) Soil and agricultural chemistry analysis. China Agriculture Press, Beijing

Bhuiyan MA, Parvez L, Islam M, Dampare SB, Suzuki S (2010) Heavy metal pollution of coal mine-affected agricultural soils in the northern part of Bangladesh. J Hazard Mater 173:384-392

Biester H, Gosar M, Covelli S (2000) Mercury speciation in sediments affected by dumped mining residues in the drainage area of the Idrija mercury mine, Slovenia. Environ Sci Technol 34:3330-3336

Bloom NS, Preus E, Katon J, Hiltner M (2003) Selective extractions to assess the biogeochemically relevant fractionation of inorganic mercury in sediments and soils. Anal Chim Acta 479:233-248

Chakraborty P, Babu PR, Vudamala K, Ramteke D, Chennuri K (2014) Mercury speciation in coastal sediments from the central east coast of India by modified BCR method. Mar Pollut Bull 81:282-288

Chen PJ, Tan SW, Wu WL (2012) Stabilization or oxidation of nanoscale zerovalent iron at environmentally relevant exposure changes bioavailability and toxicity in medaka fish. Environ Sci Technol 46: 8431-8439

Chen T, Zhou Z, Han R, Meng R, Wang H, Lu W (2015) Adsorption of cadmium by biochar derived from municipal sewage sludge: impact factors and adsorption mechanism. Chemosphere 134:286-293

CNEMC (China National Environmental Monitoring Center) (1990) The background concentrations of soil elements in China. China Environmental Science Press, Beijing 
Feng H, Han X, Zhang W, Yu L (2004) A preliminary study of heavy metal contamination in Yangtze River intertidal zone due to urbanization. Mar Pollut Bull 49:910-915

Gao XL, Chen CTA (2012) Heavy metal pollution status in surface sediments of the coastal Bohai Bay. Water Res 46:1901-1911

Hakanson L (1980) An ecological risk index for aquatic pollution control. A sedimentological approach. Water Res 14:975-1001

Hodson PV, Norris K, Berquist M, Campbell LM, Ridal JJ (2014) Mercury concentrations in amphipods and fish of the Saint Lawrence River (Canada) are unrelated to concentrations of legacy mercury in sediments. Sci Total Environ 494:218-228

Horvat M, Nolde N, Fajon V, Jereb V, Logar M, Lojen S, Jacimovic R, Falnoga I, Liya Q, Faganeli J (2003) Total mercury, methylmercury and selenium in mercury polluted areas in the province Guizhou, China. Sci Total Environ 304:231-256

Islam MS, Ahmed MK, Raknuzzaman M, Habibullah-Al-Mamun M, Islam MK (2015) Heavy metal pollution in surface water and sediment: a preliminary assessment of an urban river in a developing country. Ecol Indic 48:282-291

Jackson TA (2013) Mass-dependent and mass-independent variations in the isotope composition of mercury in a sediment core from Lake Ontario as related to pollution history and biogeochemical processes. Chem Geol 355:88-102

Leipe T, Moros M, Kotilainen A, Vallius H, Kabel K, Endler M, Kowalski N (2013) Mercury in Baltic Sea sediments-natural background and anthropogenic impact. Chem Erde-Geo Chem 73:249259

Leopold K, Foulkes M, Worsfold P (2010) Methods for the determination and speciation of mercury in natural waters-a review. Anal Chim Acta 663:127-138

Liang P, Wu S-C, Li Y-C, Li H-B, Yu G-b YS, Wong MH (2012) The effects of mariculture activities on the adsorption/desorption and chemical fractionations of mercury on sediments. Mar Pollut Bull 64:836-843

Ma J, Hintelmann H, Kirk JL, Muir DC (2013) Mercury concentrations and mercury isotope composition in lake sediment cores from the vicinity of a metal smelting facility in Flin Flon, Manitoba. Chem Geol 336:96-102

Müller G (1969) Index of geoaccumulation in sediments of the Rhine River. GeoJournal 2:108-118

Passos EA, Alves JC, dos Santos IS, Alves JPH, Garcia CAB, Spinola Costa AC (2010) Assessment of trace metals contamination in estuarine sediments using a sequential extraction technique and principal component analysis. Microchem J 96:50-57

Qiu G, Feng X, Wang S, Shang L (2005) Mercury and methylmercury in riparian soil, sediments, mine-waste calcines, and moss from abandoned $\mathrm{Hg}$ mines in east Guizhou province, southwestern China. Appl Geochem 20:627-638
Rosado D, Usero J, Morillo J (2016) Assessment of heavy metals bioavailability and toxicity toward Vibrio fischeri in sediment of the Huelva estuary. Chemosphere 153:10-17

Ryu J, Hong S, Chang WK, Khim JS (2016) Performance evaluation and validation of ecological indices toward site-specific application for varying benthic conditions in Korean coasts. Sci Total Environ 541: 1161-1171

Sahuquillo A, Rauret G, Bianchi M, Rehnert A, Muntau H (2003) Mercury determination in solid phases from application of the modified BCRsequential extraction procedure: a valuable tool for assessing its mobility in sediments. Anal Bioanal Chem 375:578-583

Singh KP, Mohan D, Singh VK, Malik A (2005) Studies on distribution and fractionation of heavy metals in Gomti river sediments - a tributary of the Ganges, India. J Hydrol 312:14-27

Sundaray SK, Nayak BB, Lin S, Bhatta D (2011) Geochemical speciation and risk assessment of heavy metals in the river estuarine sediments - a case study: Mahanadi basin, India. J Hazard Mater 186: $1837-1846$

Tang WZ, Zhao Y, Wang C, Shan BQ, Cui JG (2013) Heavy metal contamination of overlying waters and bed sediments of Haihe Basin in China. Ecotoxicol Environ Saf 98:317-323

Tessier A, Campbell PG, Bisson M (1979) Sequential extraction procedure for the speciation of particulate trace metals. Anal Chem 51: 844-851

Wu GH, Cao SS (2010) Mercury and cadmium contamination of irrigation water, sediment, soil and shallow groundwater in a wastewaterirrigated field in Tianjin, China. Bull Environ Contam Am Toxicol 84:336-341

Xiao R, Bai J, Wang Q, Gao H, Huang L, Liu X (2011) Assessment of heavy metal contamination of wetland soils from a typical aquaticterrestrial ecotone in Haihe River basin, North China. CLEAN-Soil, Air, Water 39:612-618

Yang ZF, Wang Y, Shen ZY, Niu JF, Tang ZW (2009) Distribution and speciation of heavy metals in sediments from the mainstream, tributaries, and lakes of the Yangtze River catchment of Wuhan, China. J Hazard Mater 166:1186-1194

Yin HB, Cai YJ, Duan HT, Gao JF, Fan CX (2014) Use of DGT and conventional methods to predict sediment metal bioavailability to a field inhabitant freshwater snail (Bellamya aeruginosa) from Chinese eutrophic lakes. J Hazard Mater 264:184-194

Zhang C, Yu ZG, Zeng GM, Jiang M, Yang ZZ, Cui F, Zhu MY, Shen LQ, Hu L (2014) Effects of sediment geochemical properties on heavy metal bioavailability. Environ Int 73:270-281

Zhang L, Liao Q, Shao S, Zhang N, Shen Q, Liu C (2015) Heavy metal pollution, fractionation, and potential ecological risks in sediments from Lake Chaohu (eastern China) and the surrounding rivers. Int J Environ Public Heallth 12:14115-14131 